\title{
SISTEM ABSENSI KARYAWAN RSUD KARDINAH DENGAN MENGGUNAKAN RFID
}

\author{
Dedy Setyawan, S.Kom., M.M \\ Politeknik Trisila Dharma \\ e-mail : admin@poltrisdha.ac.id / empu@poltrisdha.ac.id
}

\begin{abstract}
Abstrak : Fakta bahwa masih banyak perusahaan BUMN / BUMS masih menggunakan pencatatan kehadiran karyawan masih menggunakan manual yaitu masih menggunakan buku pencatat daftar kehadiran karyawan.pada saat masuk maupun pulang / selesai kerja. Penelitian ini bertujuan untuk membuat Rancang Bangun Perangkat Sistem Absensi Karyawan Rsud Kardinah Dengan Menggunakan RFID (Radio Frequency Identification) Berbasis Visual Basic 6.0. Sistem informasi ini memberikan kemudahan dalam melakukan absensi dan proses pengelolaan data presensi. Pengelolaan data lebih terorganisir sehingga proses penyimpanan data dan manajemen file dapat memenuhi syarat administrasi. Teknologi Radio Frrequency Identification (RFID) merupakan sebuah teknologi pengidentifikasian suatu objek dengan memanfaatkan frekuensi radio. Kelebihan yang dimiliki teknologi ini dengan teknologi identifikasi lainnya menjadi daya tarik bagi para pengembang teknologi untuk lebih memanfaatkannya. Berdasarkan hasil pengujian, sistem ini telah dapat membaca data ID melalui koneksi serial RS232 pada komputer client dan mencocokan data ID tersebut dengan Database pada komputer server yang berisi data Karyawan kemudian menampilkanya pada komputer client sebagai media informasi.
\end{abstract}

Kata Kunci : Database, Radio Frrequency Identification (RFID)

\section{Pendahuluan}

Dewasa ini sistem absensi memiliki peran penting dalam kehidupan sehari-hari terutama di lingkup kerja seperti perkantoran, pabrik, rumah sakit, sekolah, universitas, dan tempat lain yang membutuhkan sistem absensi.

RFID (Radio Frequency Identification) mulai dikembangkan sebagai salah satu teknologi baru yang akan memudahkan manusia untuk melakukan identifikasi berbagai hal, tediri dari tag berupa chip khusus yang mempunyai kode-kode informasi yang unik dan suatu reader yang berfungsi untuk membaca kode-kode pada tag tersebut.

Sistem absensi yang sering dijumpai di masyarakat biasanya bersifat mekanik, yang dilakukan dengan cara memasukkan lembar absensi yang ditandai dengan lubang atau cap berupa tanggal dan jam. Selain sistem absensi dengan menggunakan tanda tangan pada lembar absensi terdapat pula sistem absensi yang menggunakan teknologi 
terkini seperti kartu magnetik, barcode, sidik jari, RFID (Radio Frequency Identification Device) dan scan retina mata.

Pada lingkungan kerja, sebagai contoh seperti di Rumah Sakit Umum Daerah Kardinah Tegal yang terletak di Kota Tegal dimana dijumpai sistem absensi menggunakan kartu absensi yang dimasukan kedalam box jam. Karyawan cukup memasukan kartu absen tersebut pada alat yang tersedia dan alat tersebut akan mengenali mencetak waktu karyawan tersebut datang dan pulang sesuai dengan tanggal. Sistem absensi seperti ini memang sangat ringkas, cepat, dan efektif. Tetapi sering mengalami kendala pada alat dimana kartu absen tersebut masuk dan alat tersebut mencetak jam yang selalu berbeda, kartu absen masuk kedalam dan tidak bisa keluar, dan banyak kartu absen hilang yang kemungkinan diambil pengunjung pasien, terbawa atau pun terlipat.

Diharapkan dengan sistem absensi ini dapat membantu petugas absensi dalam menginput daftar karyawan yang hadir. Proses menginput menjadi lebih mudah, cepat, resiko kesalahan input juga sangat minimal karena data yang dibaca oleh petugas absensi dikomputer langsung dalam bentuk daftar absensi pada program Visual Basic.

Dari hasil pengamatan yang telah dilakukan di Rumas Sakit Umum Daerah Kardinah, maka dirancang sebuah sistem absensi berbasis mikrokontroler dengan menggunakan RFID, media penyimpanan dapat berupa memori internal dari mikrokontroler atau jika dibutuhkan memori yang lebih besar dapat menggunakan eksternal EEPROM, dan LED matriks display untuk menampilkan informasi. Sistem absensi berbasis RFID ini diharapkan mempermudah petugas bagian absensi dalam melakukan input data absensi, dan alat absensi ini sifatnya portable dan tidak memerlukan personal computer untuk dapat mengambil dan menyimpan absensi.

\section{Metode Penelitian}

Metode penelitian yang digunakan dalam pembuatan adalah :

\section{a. Jenis Data}

Dalam penelitian, teknik pengumpulan data merupakan faktor penting demi keberhasilan penelitian. Hal ini berkaitan dengan bagaimana cara mengumpulkan data, siapa sumbernya, dan apa alat yang digunakan. Jenis sumber data adalah mengenai dari mana data diperoleh. Apakah data diperoleh dari sumber langsung (data primer) atau data diperoleh dari sumber tidak langsung (data sekunder).

1) Data Primer

Data yang diperoleh dari responden melalui kuesioner, kelompok fokus, dan panel, atau juga data hasil wawancara peneliti dengan narasumber.

\section{2) Data Sekunder}

Misalnya catatan atau dokumentasi perusahaan berupa absensi, gaji, laporan keuangan publikasi perusahaan, laporan pemerintah, data yang diperoleh dari majalah, dan lain sebagainya.

\section{b. Metode Pengumpulan Data \\ 1) Observasi}


Melakukan kegiatan perancangan dan pembuatan alat penunjang yang digunakan pada Rancang Bangun Perangkat Sistem Absensi Karyawan RSUD Kardinah Dengan Menggunakan RFID (Radio Frequency Identification) Berbasis Visual Basic 6.0.

2) Wawancara

Mengadakan konsultasi dengan dosen pembimbing maupun praktisi yang berhubungan dengan permasalahan yang dibahas dalam pembuatan penelitian.

3) Studi Literatur

Dilakukan dengan cara mencari dan mempelajari referensi yang berhubungan perancangan dan pembuatan sistem absensi karyawan rsud kardinah dengan menggunakan RFID (Radio Frequency Identification).

\section{c. Pengenalan Radio Frequency Identification}

Radio Frecuency Identification (RFID) merupakan teknologi baru yang mampu mengirimkan identitas berupa digit tertentu dengan menggunakan gelombang radio. RFID sudah banyak digunakan pada pabrik dan sangat bermanfaat untuk mendukung manajemen persediaan barang. RFID dapat mengidentifikasi objek secara otomatis dan diprediksi dapat menggantikan barcode yang telah lebih dahulu kenal.

Kartu RFID terdiri dari sebuah microchip yang mempunyai sebuah antena. Di dalam kartu RFID tersebut dapat disimpan data yang ukurannya 2 kilobyte. Informasi ini bisa berisi data dari sebuah objek, identifikasi unik untuk sebuah objek dan informasi tambahan dari sebuah objek (tanggal pembuatan, tanggal pengiriman barang dan kasus Supply chain). Untuk membaca data dari kartu RFID ini diperlukan sebuah piranti pembaca yang akan memancarkan gelombang radio dan menangkap sinyal yang dipancarkan oleh kartu RFID. Tag reader meminta isi yang dipancarkan oleh signal Radio Frekuensi (RF).

Tag merespon dengan memancarkan kembali data resident secara lengkap meliputi serial nomor urut yang unik. RFID mempunyai beberapa keuntungan yang utama melebihi sistem barcode yaitu kemungkinan data dapat dibaca secara otomatis tanpa memperhatikan garis arah pembacaan, melewati bahan non-konduktor seperti kartun kertas dengan kecepatan akses beberapa ratus tag per detik pada jarak beberapa (sekitar 100) meter. Tag RFID terbuat dari microchip dengan dasar bahan dari silikon yang mempunyai kemampuan fungsi identitas sederhana yang disatukan dalam satu desain. Kemampuan tag RFID untuk membaca dan menulis (read/write), menyimpan data storage untuk mendukung enkripsi dan kontrol akses.

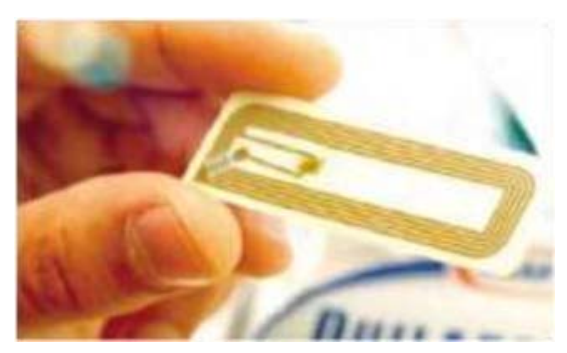


Gambar 1. RFID tag dengan silicon chip dan antena eksternal

\section{d. Cara Kerja RFID}

Label tag RFID yang tidak memiliki baterai antenalah yang berfungsi sebagai pencatu sumber daya dengan memanfaatkan medan magnet dari pembaca (reader) dan memodulasi medan magnet, yang kemudian digunakan kembali untuk mengirimkan data yang ada dalam tag label RFID. Data yang diterima reader diteruskan ke database host komputer. Pada Gambar 2.3, skema proses kerja RFID.

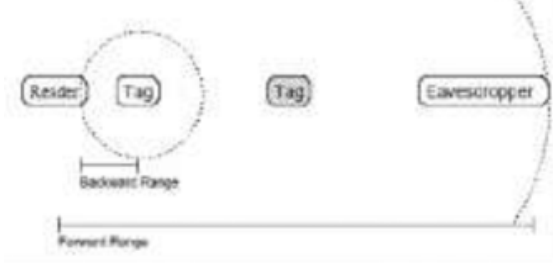

Gambar 2. Cara kerja reader RFID

Kerugian penyebaran penggunaan RFID yang universal akan memudahkan terbukanya privasi, sepionase, dan menimbulkan ancaman keamanan baru pada suatu lingkungan pabrik yang tertutup sekalipun. Penjualan eceran yang diberi label RFID dengan tag yang tidak dilindungi akan dapat dimonitor dan di-tracked oleh pesaing lain. Pabrik mengeluarkan biaya pembuatan RFID lebih tinggi supaya dapat pendukung kriptografi seperti disampaikan Stephen A. Weis "Most manufacturing processes currently deploying RFID sistems are for higher value items, allowing tag costs to be in the US\$0.50-US\$1.00 range. Tags priced in this range could support basic cryptographic primitives or tamper-resistant packaging,". Tag yang menghabiskan biaya besar ini diharapkan dapat mendukung sistem keamanan dengan kriptografi.

\section{e. Pengertian Microsoft Visual Basic}

Microsoft Visual Basic 6.0 adalah suatu bahasa pemrograman yang bersifat Object Oriented. Kata Visual Basic sendiri mempunyai makna yaitu kata Visual yang bearti menunjukkan cara yang digunakan untuk membuat Graphical User Interface (GUI), sedangkan kata Basic merupakan bagian bahasa basic (Beginners All Purpose Symbolic Instruction Code) yaitu sebuah bahasa pemrograman yang sudah banyak digunakan oleh programmer untuk menyusun sebuah aplikasi.

\section{f. Desain Sistem}

Desain dapat diartikan sebagai tahap setelah analisis dan siklus pengembangan sistem, pendefinisian dari kebutuhan-kebutuhan fungsional, persiapan untuk rancangan 
bangunan implementasi, menggambarkan bagaimana suatu sistem dibentuk yang dapat berupa penggambaran, perencanaan, pembuatan sketsa, atau pengaturan dari beberapa element yang terpisah dalam satu kesatuan yang utuh dan berfungsi, termasuk mengkonfigurasikan komponen-komponen perangkat lunak dan perangkat keras dari suatu sistem. (Jogianto HM, 2001 : 1997).

\section{g. Teori Database}

Basis data (Data Base) adalah kumpulan dari berbagai data yang saling berhubungan satu dengan yang lainnya. Basis data tersimpan di perangkat keras, serta dimanipulasi dengan menggunakan perangkat lunak. Pendefinisian basis data meliputi spesifikasi dari tipe data, struktur dan batasan dari data atau informasi yang akan disimpan. Database merupakan salah satu komponen yang penting dalam sistem informasi, karena merupakan basis dalam menyediakan informasi pada para pengguna atau user.

Penyusunan Data Base meliputi proses memasukkan data kedalam media penyimpanan data dan diatur dengan menggunakan perangkat Sistem Manajemen Basis Data (Database Management System DBMS). Manipulasi basis data meliputi pembuatan pernyataan (query) untuk mendapatkan informasi tertentu, melakukan pembaharuan atau penggantian (update) data, serta pembuatan report data.

\section{h. Pengertian Microsoft Access}

Microsoft access (Microsoft Office Access) adalah sebuah program aplikasi basis data komputer relasional yang ditujukan untuk kalangan rumahan dan perusahaan kecil hingga menengah, Aplikasi ini merupakan anggota dari beberapa aplikasi microsoft office, selain tentunya microsoft word, microsoft excel, dan microsoft powerpoint. Aplikasi ini menggunakan mesin basis data microsoft jet database engine, dan juga menggunakan tampilan grafis yang intuitif sehingga memudahkan pengguna.

Microsoft access dapat menggunakan data yang disimpan di dalam format microsoft access, microsoft jet database engine, microsoft SQL Server, Oracle Database, atau semua kontainer basis data yang mendukung standar ODBC. Para pengguna/programmer yang mahir dapat menggunakannya untuk mengembangkan perangkat lunak aplikasi yang kompleks. Sementara para programmer yang kurang mahir dapat menggunakannya untuk mengembangkan perangkat lunak aplikasi yang sederhana. Access juga mendukung teknik-teknik pemrograman berorientasi objek, tetapi tidak dapat digolongkan ke dalam perangkat bantu pemrograman berorientasi objek.

\section{Hasil dan Pembahasan}

\section{a. Sekilas Pengenalan Perusahaan}


RSU Kardinah didirikan oleh adik dari RA. Kartini yang bernama Raden Ayu Adipati Ariyo Kardinah. R.A.A.A. Kardinah lahir di Jepara pada 1 Maret 1881 / 30 Maulud 1881. Pada usia 12 R.A.A.A. Kardinah melihat adanya perbedaan antara pelayanan masyarakat pribumi / miskin dengan masyarakat yang berduit / bangsawan. Untuk pasien yang berduwit selalu mendapatkan pelayanan extra / serba istimewa \& tidur di kamar empuk. Sedangkan untuk pasien miskin hanya tidur di atas tiker yangada di tanah. Pada tahun 1903 - 1929 RA. A.A Kardinah selalu menyertai namanya RMAA Sejitno Rehonegoro $\mathrm{X}$ yang menjabat sebagai Bupati \& ditugaskan di Tegal. Bahkan pada tahun-tahun tersebut R.A.A.A Kardinah berkiprah untuk kepentingan kaum wanita seperti kakanya R.A. Kartini. Sementara itu baliau juga membuat sebuah buku dan buku-buku tersebut juga dijual ke Pemerintah Belanda sejumlah F 16.000. F 16.000 uang dari penjualan buku sebagai modal awal pembangunan RSU Kardinag sekitar tahun 1920. Pada tahun 1971 tepatnya 4 Juli 1971 R.A.A.A Kardinah Wafat dan di makamkan di daerah Adiwerna / Pesayangan / Kab. Tegal.

\section{b. Entity Relationship Diagram (ERD)}

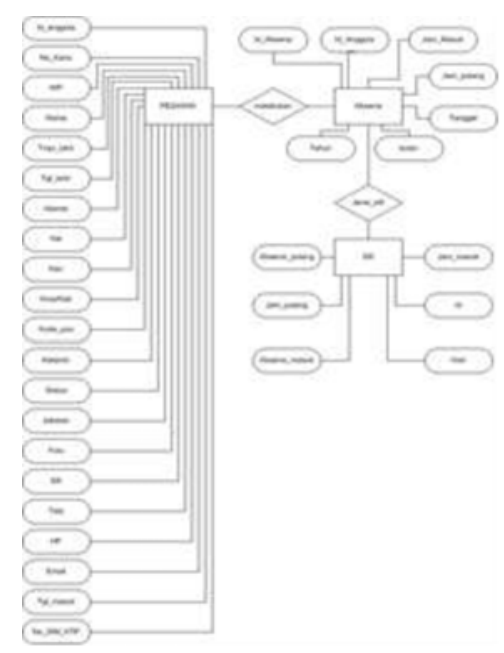

Gambar3. ERD Sistem Absensi Pegawai

\section{c. Diagram Konteks}

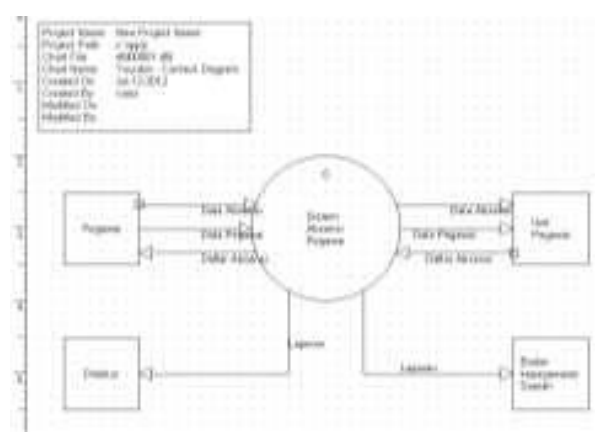


Gambar 4. Diagram Konteks Sistem Absensi Pegawai

\section{d. Rancangan Dialog Layar}

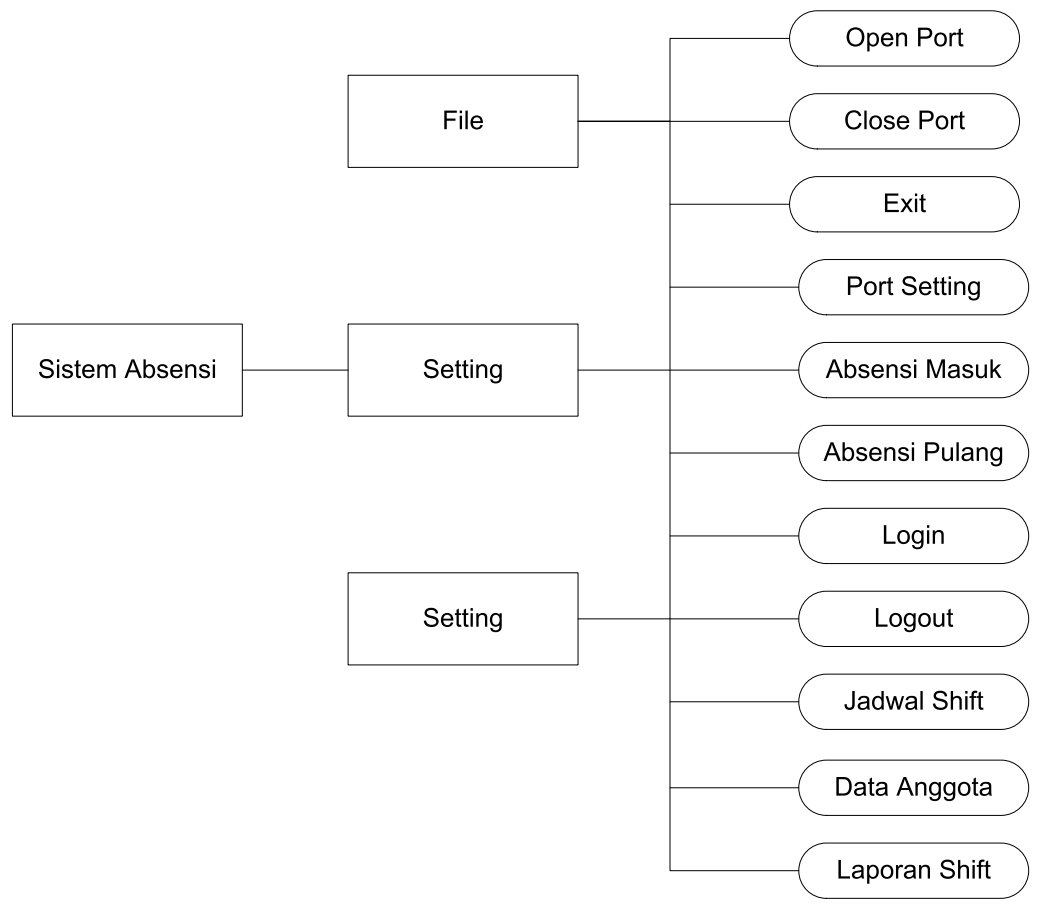

Gambar 5. Struktur Tampilan Sistem Absensi

\section{e. Pembuatan program}

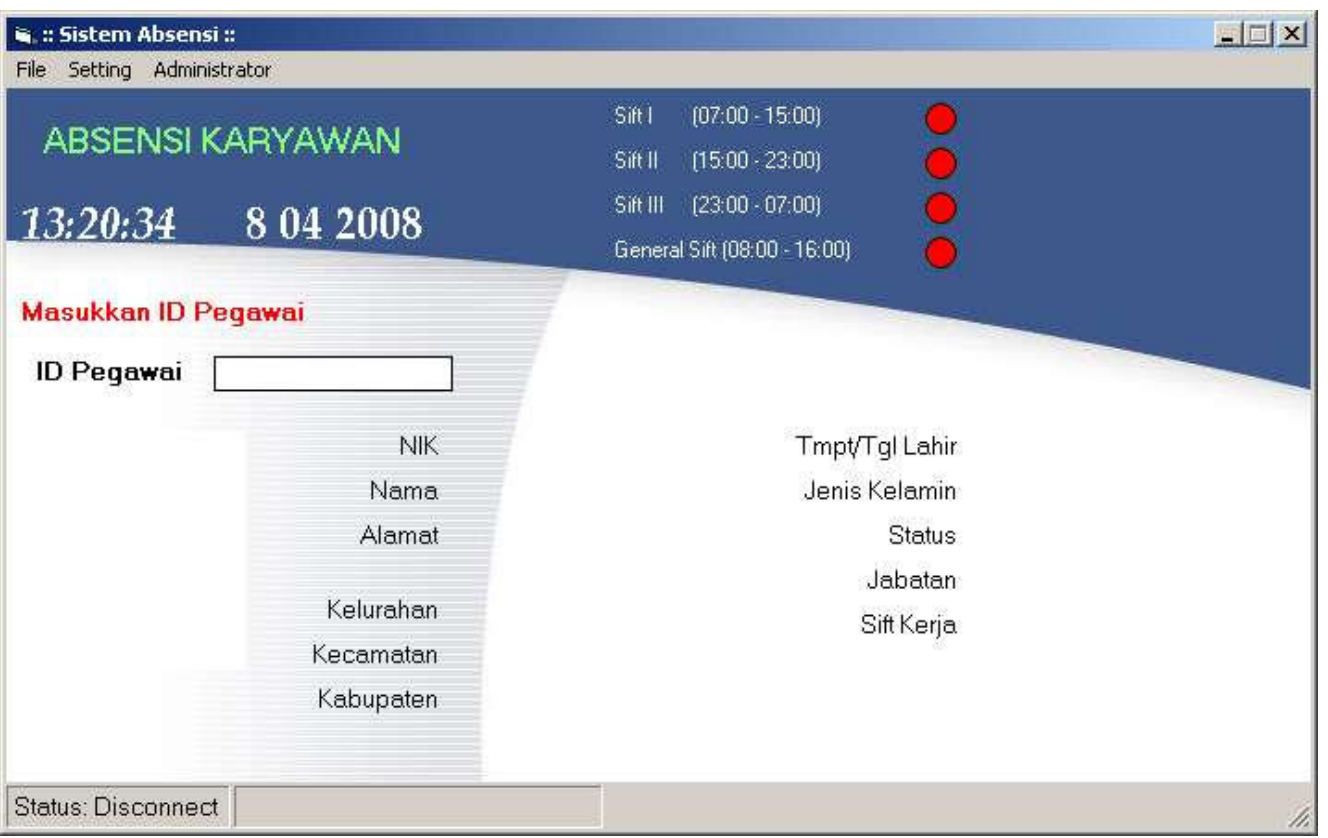




\section{Gambar 6. Sistem Absensi}

Program ini akan bekerja jika ada karyawan yang melakukan absen masuk maupun absen keluar sesuai dengan konfigurasi yang dilakukan oleh administrator.

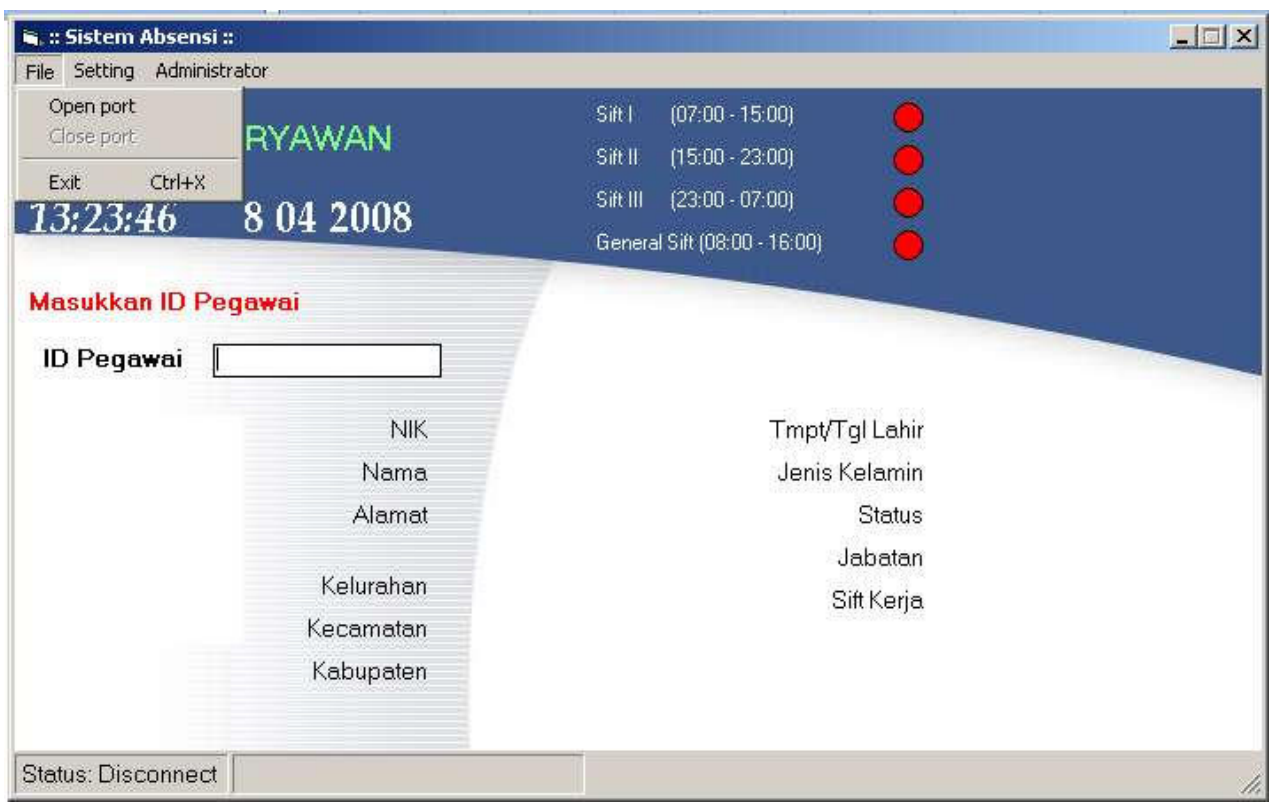

Gambar 7. Menu File Sistem Absensi

\section{Kesimpulan}

Dari hasil penelitian ini maka dapat disimpulkan sebagai berikut :
a. Pembuatan sistem absensi karyawan RSUD Kardinah Kota Tegal dengan menggunakan RFID.
b. Pembuatan sistem absensi karyawan RSUD Kardinah Kota Tegal yang akurat, cepat, tepat, efisien, dan murah.

\section{Daftar Pustaka}

[1] Abdul Kadir, Panduan Praktis Mempelajari Aplikasi Mikrokontroler dan Pemogramannya Menggunakan Arduino, CV ANDI OFFSET, Yogyakarta, 2013.

[2] Andi Nalwan, Paulus, Panduan Praktis Teknik Antarmuka dan PemrogramanMikrokontroler AT89C51, PT Elex Media Komputindo, Jakarta 2003.

[3] Agfianto Eko Putra, Belajar Mikrokontroler AT89C51/52/55, Penerbit Gava Media, Yogyakarta, 2002.

[4] Budiharto, Widodo, Interfacing Komputer dan Mikrokontroler, PT Elex Media Komputindo, Jakarta 2004.

[5] Finkenzeller, Klaus. 2003. RFID Handbook : Fundamentals and Applications in Contactless Smart Cards and Identification,2nd Edition, London: John Wiley \& Sons Finken. 
[6] Henirich, Claus, 2005. RFID and Beyond : Growing Business Through Real Word Awareness, Canada : Wiles Publishing.

[7] Landt, J, 2005. The History of RFID, IEEE Potensials, Vol.24 No. 4 pp 8-11.

[8] PemrogramanMikrokontroler AT89C51, PT Elex Media Komputindo, Jakarta 2003.

[9] Agfianto Eko Putra, Belajar Mikrokontroler AT89C51/52/55, Penerbit Gava Media, Yogyakarta, 2002.

[10] Petruzella, Frank D, Elektronika Industri Edisi II, Terjamahan dari Industrial Electronics oleh Sumanto, Drs. M.A., ANDI Yogyakarta, Yogyakarta 2001.

[11] S.W Amos, Kamus Elektronika, PT Elex Media Komputindo, Jakarta 1996.

[12] Systems Analysis Design UML Version 2.0 An Object-Oriented Approach, John Wiley \& Sons, United States of America,2009.

[13] Zaks, Rodnay, Teknik Perantaraan Mikroprosesor Edisi Ketiga, Penerbit Erlangga, Jakarta 1993 